\title{
Characterization of soil handling with mould-board ploughs
}

\author{
J. K. Kouwenhoven and R. Terpstra \\ Department of Agricultural Engineering, Laboratory of Soil Tillage, Agricultural Uni- \\ versity, Wageningen, the Netherlands
}

Received: 18 February 1972

\section{Summary}

A rapid method for measuring soil displacement on ploughing, in relation to distance to the furrow-wall, was developed and applied in a large number of field trials with different mould-boards, soils and speeds in order to characterize the effect of ploughing.

The method based on the use of tracers placed across the cutting plane of the ploughshare was applied in 56 cases.

It was difficult to avoid some confusion of variables. Measurements close to the sides of the furrow-slice were also a problem. Moreover, unexpected variables such as the age of the soil seemed to play a part. Therefore, only linear relationships seemed to be significant, being mostly in accordance with reality.

From these relationships the elongation can be calculated in a simple way. In order to record deformation within the furrow-slice, markers were inserted systematically into the furrow-slice. The elongation appeared to be a characteristic of the deformation within the furrow-slice and gauge for the crumbling of the furrow-slice. The furrowslice was most severely deformed at the bottom and close to the point of the ploughshare. Upheaval, explaining the increase in pore space by ploughing, and elongation explaining crumbling, are important characteristics of ploughing.

\section{Introduction}

The displacement of soil by mould-board ploughs has been previously investigated, e.g. by Feuerlein (1960-1969), Kuipers et al. (1966), Nichols and Reed (Ashby) (1934) and Söhne (1956).

The initial and final positions of soil particles were marked by markers placed into the furrow-slice. After ploughing, the markers were traced and their position was measured. In order to facilitate the tracing of the markers, some were supplied with threads or were made radioactive. The radioactive markers were traced with a Geiger-counter. Less direct methods were used by Rid and Süss (1960) and Steenberg and Njøs (1964) by placing radioactive material on the surface of the soil. The number of observations was limited because of the laborious methods. The results, therefore, were not very reliable. A quicker and simpler method was therefore required to find the factors influencing the result of ploughing. This method was found by placing the markers at the bottom of the furrow-slice in the intersecting plane of the plough-share. After ploughing, one part of the marker was found in the bottom of the furrow and the other on the ploughed land (Fig. 1). The foreward (fw), sideways (sw) and upward (uw) displacement was measured in relation to the distance of the furrow-wall (dfw). Measurements were 


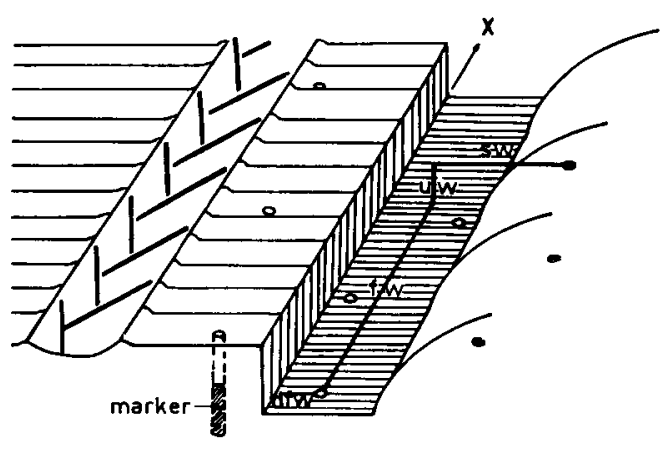

Fig. 1. Schematic drawing of displacement measurement at ploughing (according to Kuipers, 1966); $\mathrm{fw}=$ forward; $\mathrm{sw}=$ sideways, $\mathrm{uw}=$ upward displacement; $\mathrm{dfw}=$ distance to furrow-wall.

carried out in the field in co-operation with ILR ${ }^{1}$. In addition, some model experiments were done in the ILR soil bin. Here the markers were placed systematically in the furrowslice, through which the displacement and deformation of the furrow-slice by the plough could be observed.

\section{Procedure and equipment}

\section{Markers}

Because of the intention to cut the markers, placed at the bottom of the furrow-slice, with the share of the plough, oblong markers were preferred. Sticks of modelling clay $(1=10 \mathrm{~cm})$ and chalk $(1=8 \mathrm{~cm})$ were considered. Although the modelling clay was more like the soil, the chalk was preferred because the clay stick was often left uncut on the sandy soil and carried along by the plough-share, and also because it was difficult to press the clay marker in the hole.

In the field, the markers were inserted in a hole ( $\varnothing$ hole $=\varnothing$ marker), pricked into the furrow-slice, until an adjustable depth of $(\mathrm{pd}+1 / 21)$ had been reached (Fig. $2 ; \mathrm{pd}=$ ploughing depth; 1 = length of the marker). In doing so, the plough-share would theoretically cut the markers exactly in half. The markers were evenly placed at any distance to the furrow-wall and in the direction of travel at a distance of about $50 \mathrm{~cm}$ from each other.

In the soil bin, beads ( $\varnothing 6.5 \mathrm{~mm}$ ), supplied with threads and reference numbers, were used as markers. They were placed by the pricker in previously arranged positions according to a reference system $(X, Y, Z)$, in planes $(Y Z)$ at an equal distance from each other and perpendicular to the direction of travel (X) (Fig. 3).

\section{Measurements}

In the field, the displacement of the markers was measured by a co-ordinate system made up of three laths perpendicular to each other. Some difficulties were caused by the unevenness of the furrow-bottom. Moreover, some positions at the sides of the furrowslice could not be measured.

One hundred measured displacements per plot was aimed at; a mean of 88 was $\mathrm{ob}$ tained. Because of variation in the ploughing depth and the falling back of lumps of

1 Instituut voor Landbouwtechniek en Rationalisatic (Institute of Agricultural Engineering and Rationalization) at Wagenungen. 


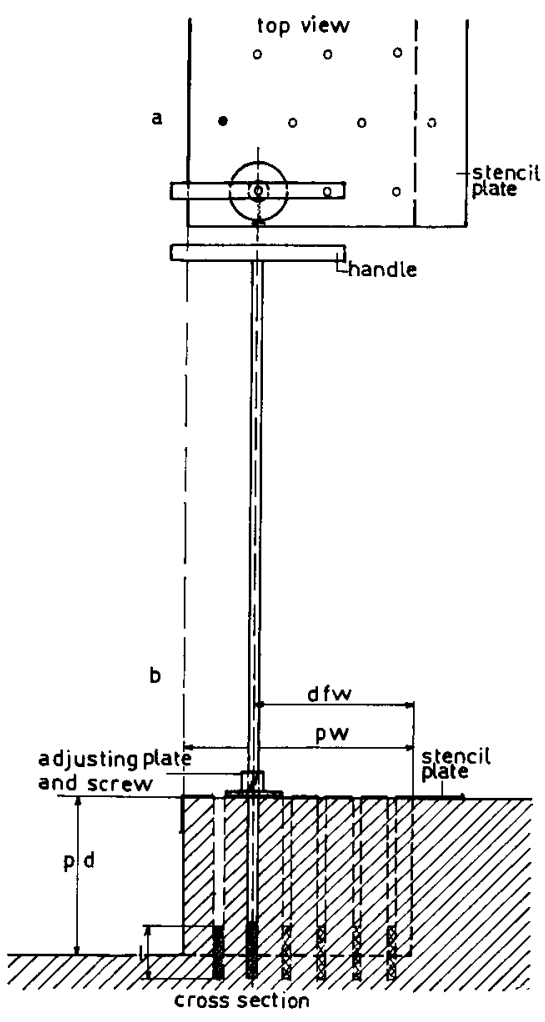

Fig. 2. Systematic insertion of tracers into the furrow-slice by means of a pricker and a stencil-plate in top-view (a) and in cross-section (b); pd = ploughing depth; $1=$ length of the marker; dfw $=$ distance of the burrow-wall; pw = ploughing with.

soil with markers, an estimated excess of $50 \%$ of tracers had to be placed, and most of the displacements measured came from the middle of the furrow-slice (Fig. 4).

The position of the markers after ploughing was measured very accurately in the soil bin by the same co-ordinate system that was used to arrange them. This system consisted of a rail of the soil bin (X), the bridge across the soil bin (Y) and the pricker (Z).

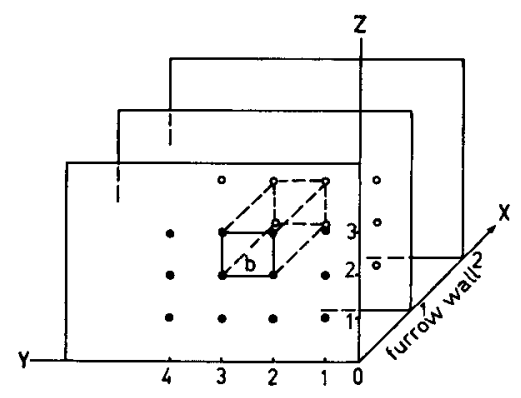

Fig. 3. Systematic insertion of tracers in planes (ZY) perpendicular to the direction of travel $(\mathrm{X}) ; \mathrm{b}=$ block. 


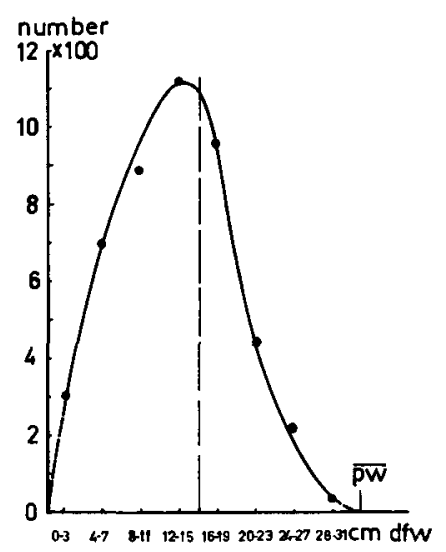

Fig. 4. Distribution of all measured displacements (4671) over the furrow-slice; $\mathrm{pw}=$ mean ploughing width; $\mathrm{dfw}=$ distance of the furrow-wall.

\section{Variables}

Ploughs. Seventeen different ploughs were used in the field. Technical data were not always available. These ploughs were:
1. Krone
10. Eberhardt R4256
2. Goudland
11. Hert 35A
3. Ransomes
4. Rumpstad 111 'steep'
12. Rumptstad
5. Ransomes TCN3K
13. Cappon stubble-plough
6. Rumptstad 108R
14. Rumptstad stubble-plough
7. Ransomes SCN9K
15. Rumptstad 111 'less steep'
8. Mélotte
16. Rumptstad 108 'less steep'
17. Rumptstad 108 'steep'
9. Krone U9

In the soil bin a model Rumptstad plough, scale $1: 2$, fitted with a perspex mouldboard, was used. The mean ploughing depth (pd) was $11.5 \mathrm{~cm}$ and the ploughing width (pw) $17.0 \mathrm{~cm}$. The ploughs used in co-operation with ILR have been described by Poesse and van Ouwerkerk (1967) and Klooster (1968).

Soils. Ploughing in the field has taken place on 10 different soils, in the autumn and spring of the years 1964-1967, under rather wet conditions. These soils are given below, with the percentage $<16 \mu \mathrm{m}$ between brackets:
1. Sandy clay Willemstad $(25 \%)$
2. Loess
Schinveld
$(25 \%)$
6. Sandy clay Driel
$(25 \%)$
3. Sand
Ede
$(-)$
7. Heavy clay Elst
4. Loess
Wijnandsrade $(28 \%)$
8. Sand
Droevendaal (- )
5. Clay
Haarweg
$(55 \%)$
9. Clay
Westmaas
$(41 \%)$
10. Clay Dronten
(44\%)

The ILR soil bin was filled with clay $(40 \%)$, having an average moisture content during cultivation of $19 \%$. As the moisture content at pF 2 (a suction of $100 \mathrm{~cm}$ of water) was $20 \%$, practical conditions were well approximated.

Driving speeds. The driving speeds in the field varied from $1-10 \mathrm{~km} / \mathrm{h}$; in the soil bin the driving speed was $3.5 \mathrm{~km} / \mathrm{h}$. 


\section{Results of field trials}

Relationship between displacement of the soil and distance to the furrow-wall When the relationship between displacement and the distance to the furrow-wall was investigated, only the functions of the first and second degree were considered, although with a more even distribution of the measured displacements over the width of the furrow-slice, a function of the third degree could be possible.

With the high concentration of the measured markers in the middle of the furrowslice (Fig. 4), the square part of the function did not contribute very much to the explanation of the variance of the original figure (Table 1).

Therefore, linear relationships were preferred (Fig. 5). From Fig. 5 and Table 3 it appears that the mean sideways displacement $(32.7 \mathrm{~cm}$ ) equalled the mean ploughing width $(32.6 \mathrm{~cm})$; As dfw $=0$, the sideways displacement $(70.6 \mathrm{~cm})$ was a little more than twice the ploughing width $(2 \times 32.6 \mathrm{~cm})$. Table 1 shows the striking fact, that the percentage explained by the rectilinear relationship of the sideways displacement was much higher, than that of the displacement in the other directions. Other factors also probably play a part.

Table 1. The percentage of the original variance, explained by a linear relationship with the distance to the furrow-wall.

\begin{tabular}{lll}
\hline Direction of displacement & Linear & Linear + quadratic \\
Forward (fw) & 29 & 30 \\
Sideways (sw) & 65 & 66 \\
Upward (uw) & 44 & 46 \\
\hline
\end{tabular}

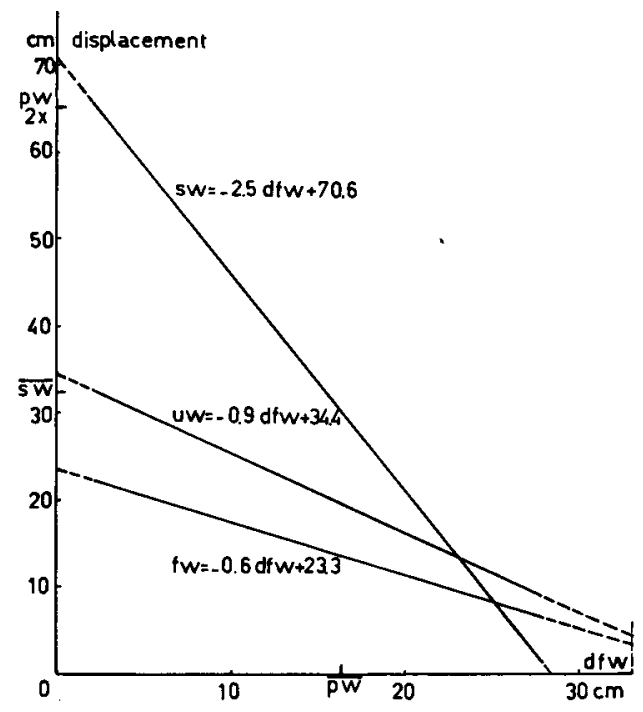

Fig. 5. Mean forward (fw), sideways (sw) and upward (uw) displacement in relation to the distance to the furrow-wall (dfw); $\mathrm{pw}=$ ploughing width. 
Table 2. Influence of the plough and the soil on the turning angle $(\alpha)$ and the transport angle $(\beta)$.

\begin{tabular}{|c|c|c|c|c|c|c|}
\hline Soil & & Sand & Loess & $\begin{array}{l}\text { Sandy } \\
\text { clay }\end{array}$ & Clay (9) & Clay (10) \\
\hline Turning angle & $a$ & $156^{\circ} 09^{\prime}$ & $145^{\circ} 25^{\prime}$ & $143^{\circ} 11^{\prime}$ & $138^{\circ} 14^{\prime}$ & $148^{\circ} 22^{\prime}$ \\
\hline Transport angle & $\beta$ & $27^{\circ} 23^{\prime}$ & $22^{\circ} 05^{\prime}$ & $25^{\circ} 32^{\prime}$ & $31^{\circ} 33^{\prime}$ & $20^{\circ} 17^{\prime}$ \\
\hline
\end{tabular}

Turning angle $(\alpha)$ and transport angle $(\beta)$

According to Nichols and Reed (1934) and Söhne (1956) the transport angie $(\beta)$ should be about $45^{\circ}$ in relation to the primary shear planes in front of the plough at an angle of about $45^{\circ}$. Both angles are on the average $\left(\alpha=149^{\circ}\right.$ and $\left.\beta=22^{\circ}\right)$. A strong deviation from $45^{\circ}$ for the angle of transport is shown. Feuerlein (1962 and elsewhere) preferred a turning angle of $135^{\circ}$. To achieve this angle, the relationship between ploughing width and depth should be $1.4: 1$, in the case of a non-crumbling furrow-slice. With an average ploughing width of $32.6 \mathrm{~cm}$ and a ploughing depth of $22.9 \mathrm{~cm}$, the required relationship was certainly achieved, but the mean turning angle turned out to be $149^{\circ}$. This was probably caused mainly by the crumbing of the soil. The lighter soils showed greater turning angles (Table 2), especially at higher speeds (Feuerlein, 1962; Söhne, 1959) and smaller transport angles. The ploughs themselves influenced the angles considerably.

\section{Mean displacements}

The mean displacements of the soil are the displacements if $\mathrm{dfw}=1 / 2 \mathrm{pw}$; ( $\mathrm{pw}=$ ploughing width). The influence of the ploughs on mean displacement of the soil was investigated. The mean displacement showed a tendency to increase with an increasing travelling speed and the percentage $<16 \mu \mathrm{m}$ : Fig. 6 .
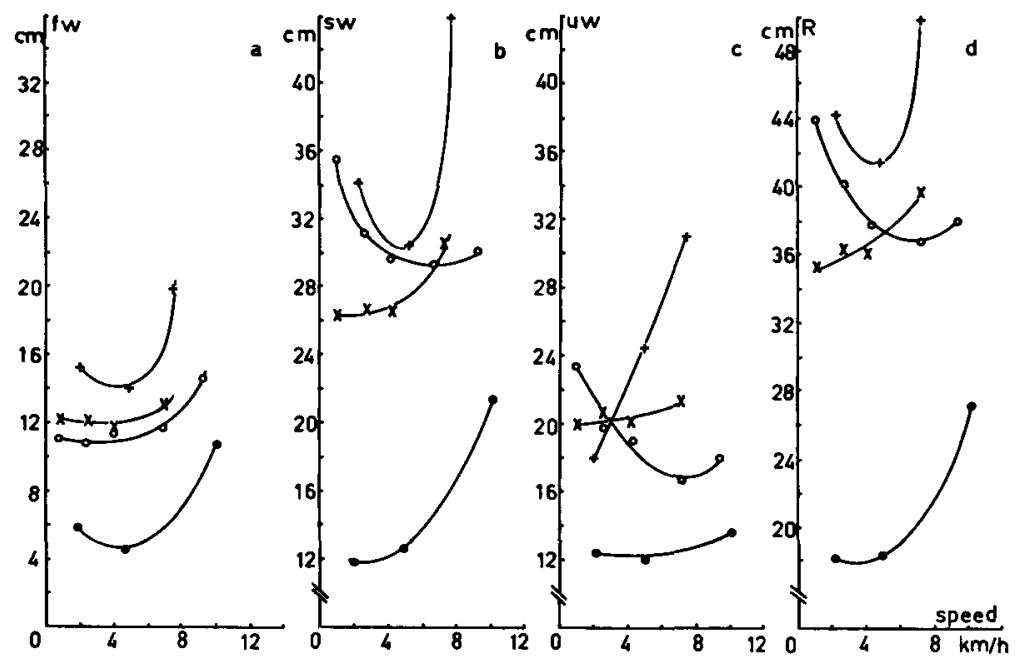

Fig. 6. Mean displacements (in relation to the $\mathrm{dfw}$ ) as influenced by the speed of travel with different ploughs and soils; $\mathrm{fw}=$ forward, $\mathrm{sw}=$ sideward; uw = upward displacement. $\mathrm{plough} 3$ : sand (3); O plough 4, 5, 6, 7: loess (4); + plough 1: sandy clay (1); plough 15, 16:clay $(9,10)$. 
Table 3. The average displacement of the soil by mould-board ploughs $(\mathrm{dfw}=1 / 2 \mathrm{pw})$

\begin{tabular}{lll}
\hline Direction of displacement & Displacement $(\mathrm{cm})$ & Mean deviation d $(\mathrm{cm})$ \\
Forward & 15.7 & 5.7 \\
Sideways & 32.7 & 8.3 \\
Upward & 19.5 & 2.9 \\
Resultant & 41.5 & 8.9 \\
\hline
\end{tabular}

The results best resembled the sw-displacement. Besides the plough, the soil and the driving speed, other factors such as maturity of the soil can influence the average displacement (Table 2). Soil 10, though as heavy as soil 9 , behaved like a much lighter soil. This was confirmed by its specific resistance, measured by ILR $(\mathrm{v}=4.3 \mathrm{~km} / \mathrm{h}$; ploughs 15,16 and 17). This came to $36 \mathrm{~kg} / \mathrm{dm}^{2}$ for soil 10 to $54 \mathrm{~kg} / \mathrm{dm}^{2}$ for soil 9 . Fig. 6 also shows a minimum transport at a driving speed of about $4-5 \mathrm{~km} / \mathrm{h}$. This speed could be considered as the optimum working speed of the plough.

The means of all measurements are given in Table 3 .

Transport of the furrow-slice into the direction of travel

The transport of the furrow-slice into the direction of travel is the forward displacement if dfw $=$ pw. In the field, the average of all results came to $6.2 \mathrm{~cm}$, in the soil bin $6.5 \mathrm{~cm}$ was noted.

The influence of the plough and the soil on the transport of the slice by three ploughs is shown in Table 4. The furrow-slice of soil 10 was transported twice as far as that of soil 9 .

As can be concluded from Fig. $7 \mathrm{~b}$, the transport of the furrow-slice diminished with heavier soils. Soil 10, therefore, behaved once more like a less heavy soil than soil 9 .

A minimum transport of the furrow-slice was found at a speed of not more than $3 \mathrm{~km} / \mathrm{h}$. Higher speeds were attended by an increased transport.

\section{Elongation}

Elongation is defined as the increase of the distance between two points (at certain dfw's) caused by ploughing, as a percentage of the original distance. The elongation in the field stands at $97 \%$ on the average. This agreed with the $92 \%$ for a clay soil and $135 \%$ for a sandy soil, mentioned by Kuipers et al. (1966). Elongation can be defined as follows (Fig. 8): Distance after ploughing minus distance before ploughing/Distance before ploughing $\times 100=\%$ elongation.

Table 4. Transport of the furrow-slice into the direction of travel $(\mathrm{cm} ; \mathrm{dfw}=\mathrm{pw})$ as influenced by the plough and the soil ( $\mathrm{v}=4.3 \mathrm{~kg} / \mathrm{h}$ )

\begin{tabular}{|c|c|c|c|c|}
\hline Plough No & 15 & 16 & 17 & Mean \\
\hline $\begin{array}{cc}\text { Soil Westmaat } & (9) \\
\text { Dronten } & (10)\end{array}$ & $\begin{array}{l}1.5 \\
2.6\end{array}$ & $\begin{array}{l}4.8 \\
6.5\end{array}$ & $\begin{array}{l}0.8 \\
4.2\end{array}$ & $\begin{array}{l}2.4 \\
4.4\end{array}$ \\
\hline Mean & 2.0 & 5.6 & 2.5 & 3.4 \\
\hline
\end{tabular}




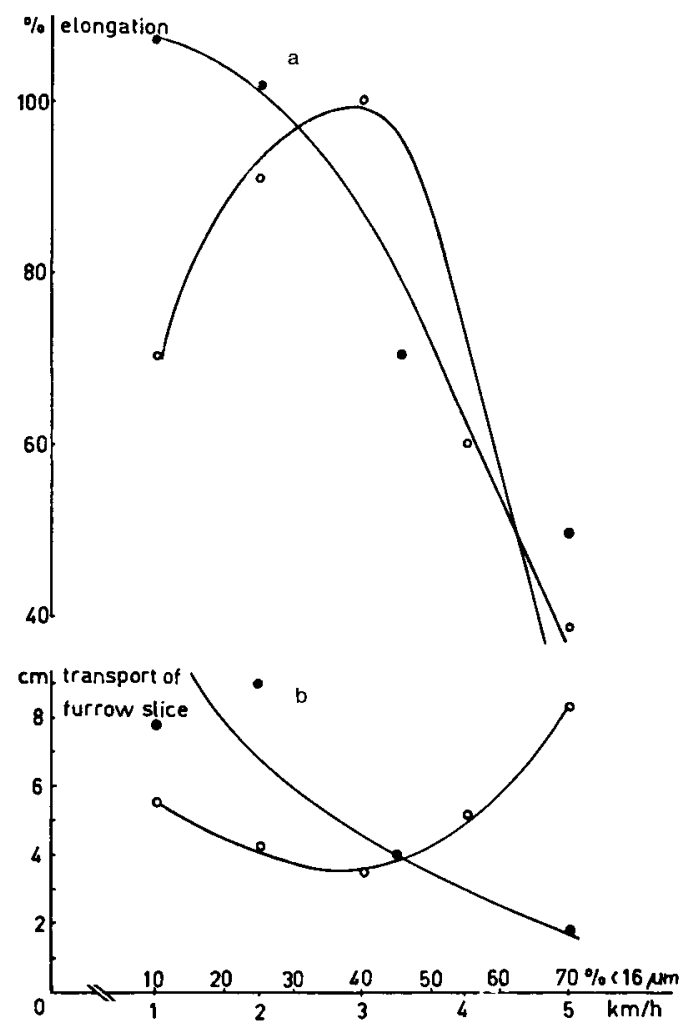

Fig. 7. Transport of the furrow-slice into the direction of travel (a) and elongation (b) Variables: $\%<16 \mu \mathrm{m}$; O $\mathrm{v}(\mathrm{km} / \mathrm{h})$.

If the relationship between the displacement in relation to the dfw is rectilinear, the elongation can be formulated by the equation:

$100\left(\sqrt{a^{2}+(b-)^{2}+c^{2}}-1\right)=0$ elongation. In this equation $a, b$ en $c$ are the

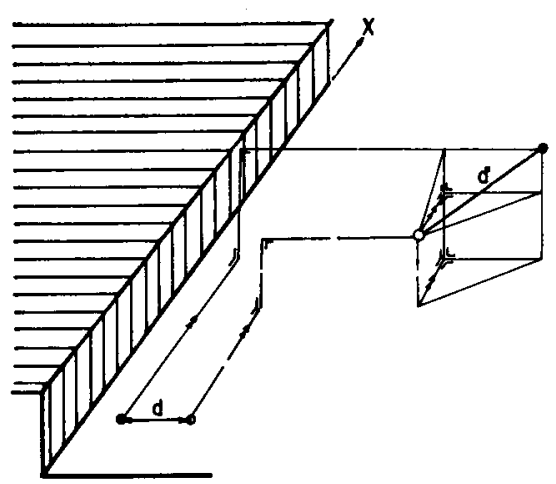

Fig. 8. Elongation illustrated: $\left(\mathrm{d}^{\prime}-\mathrm{d}\right) / \mathrm{d}=\%$ elongation. 
regression coefficients (r.c.) of the straight lines already mentioned ${ }^{1}$. If one of these displacement relationships is not rectilinear the elongation will be related to the $\mathrm{dfw}$. Because, in the field, the furrow-wall was chosen as the referring level, only the elongation between those points situated perpendicular to the ploughing direction, at the bottom of the furrow, could be measured. The correlation between regression coefficient sw $_{\text {(r.c. }}$ sw) and the elongation was strong, the other correlations, r.c. fw $_{\mathrm{w}}$, r.c. $\mathrm{uw}_{\mathrm{w}}$ and elongation were less strong. Numerically, the share of the r.c.uw in the elongation is rather important, but generally the value was about 1 , so that the variation was rather small. The r.c.fw was, in most cases, substantially smaller than 1 , which was attended with a limited influence exerted on the elongation. The elongation can be approximated by the empirically found equation:

110 (r.c.sw -2$)+30=\%$ elongation.

The elongation was influenced by the type of the plough and decreased with an increasing percentage $<16 \mu \mathrm{m}$ of the soil. An increasing driving speed caused a maximum elongation at a speed of $3-4 \mathrm{~km} / \mathrm{h}$ (Fig. $7 \mathrm{a}$ ). The high percentages of the elongation mentioned cause a suspicion of a non-uniform elongation of the furrow-slice. As can be seen in practice the furrow-slice is often put down in big lumps, which are only slightly elongated within themselves (Fig. 12). Moreover these lumps are frequently turned more or less in relation to the ploughing direction (Söhne, 1956). This was not taken into account when the results from the field trials were worked out.

Therefore, a study of the deformation within the furrow-slice, caused by the ploughing action, was necessary.

\section{Results of soil bin experiments}

In a soil bin markers were placed in a cubical arrangement as indicated in Fig. 3. Of each cubical element the changes in the right angles at the corners (1A) were calculated and the changes of the length of all lines $(\Delta \mathrm{L})$ in $\mathrm{X}, \mathrm{Y}$ and $\mathrm{Z}$ direction of the connecting lines between adjacing markers. Moreover the change in volume $(A \mathrm{~V})$ of each cubical element was determined.

If $\Delta \mathrm{L}$ is zero, a change in the right angles will give a volume decrease. If $\Delta \mathrm{A}$ is zero a change in length will give a change in volume, either a volume increase if there is an elongation, or a volume decrease if a shortening is observed.

When the soil did not crumble, $\Delta \mathrm{L}$ and $\triangle \mathrm{A}$ (as a mean value of all the line elements and corners present in a cube) were relatively small. In Fig. 9a the positive relation between this mean $\angle \mathrm{L}$ (elongation) and $\angle \mathrm{V}$ is shown, and in Fig. 10a the tendency of a negative relation between the mean value of $\Delta \mathrm{A}$ and $\Delta \mathrm{V}$. Fig. 11 shows the direction of deformation of a cubical element.

In an experiment where the soil was partly crumbled a separation was made between markers in crumbled and in not-crumbled parts of the soil. The numeral values in the crumbled parts of both $\Delta \mathrm{A}$ and $\Delta \mathrm{L}$ were much higher (Fig. $10 \mathrm{c}$ ), and in general higher values of $\Delta \mathrm{A}$ were accompanied by higher values of $\Delta \mathrm{L}$. If $\Delta \mathrm{L}$ was higher than $20 \%$ the soil was crumbled. In Fig. $10 \mathrm{~b}$ it can be seen that in the not crumbled blocks the negative relation between $\triangle \mathrm{A}$ and $A \mathrm{~V}$ is still present. In spite of the positive mean values of $\Delta \mathrm{L}, \Delta \mathrm{V}$ is in most blocks negative, which means that these not crumbled blocks were compacted. In the crumbled part a very high value for $\Delta \mathrm{A}$ might be expected from the

$1 \quad \mathrm{a}=\mathrm{r} \cdot \mathrm{c}_{\mathrm{fw}} ; \mathrm{b}=\mathrm{r} \cdot \mathrm{c}_{\mathrm{sw}} ; \mathrm{c}=\mathrm{r} \cdot \mathrm{c}_{\mathrm{uw}}$. 

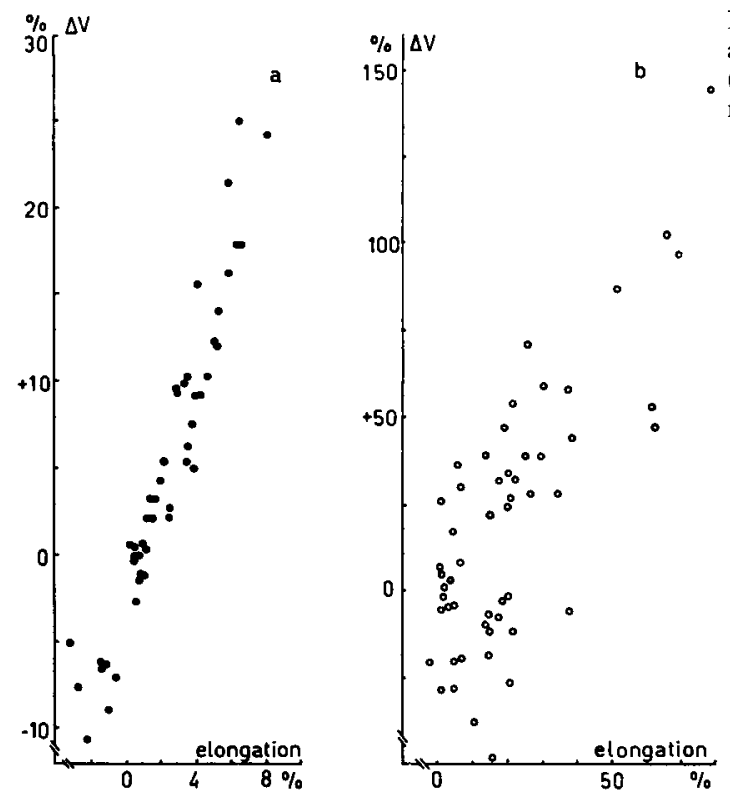

Fig. 9. The relationship between $\triangle V$ and elongation with a non-crumbled (a) - (c. $r=$ c. 0.95) and a crumbled (b) (c. $r=$ c. 0.75 ) furrow-slice.

extremely high values of $\Delta \mathrm{L}$, but obviously the also high values of $\lambda \mathrm{A}$ have a restrictive effect. However, the relation between $\triangle \mathrm{A}$ and $\angle \mathrm{V}$ is positive in the crumbled soil, because of the high values of $\Delta \mathrm{L}$. In Fig. $9 \mathrm{~b}, \Delta \mathrm{L}$ for this partly crumbled soil is plotted to $A \mathrm{~V}$ to show that the elongation in a crumbled soil has a much weaker relation with volume increase than in a not crumbled soil (Fig. 9a). Elongation is a good indicator for crumbling, not for increase of volume, because large elongations are accompanied

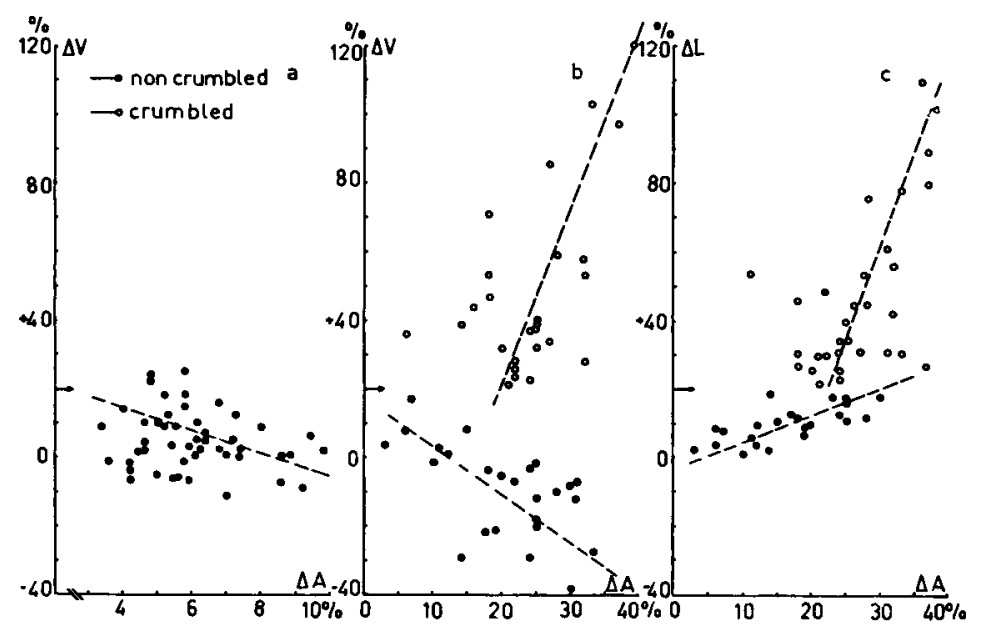

Fig. 10. The relationship between $\triangle A$ and $\triangle V$ with a crumbled (b) and a non-crumbled (a) furrow-slice, explained from the relationship between $\triangle A$ and $\triangle L$ (c). 


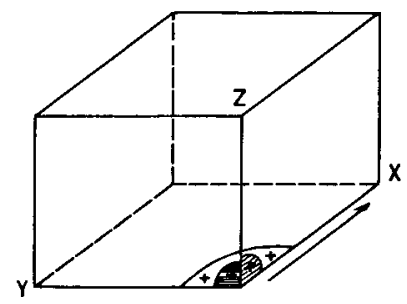

Fig. 11. Change of the angles $(\triangle A)$ in the three planes perpendicular to each other for a non-crumbling furrow-slice.

Table 5. The elongation (\%) of the furrow-slice in cross section; mean per block.

\begin{tabular}{|c|c|c|c|c|c|c|c|c|}
\hline \multirow[t]{2}{*}{ Direction $^{1}$} & \multicolumn{4}{|c|}{ Non-crumbled furrow-slice } & \multicolumn{4}{|c|}{ Crumbled furrow-slice } \\
\hline & $\mathrm{Y}_{4 / 3}$ & $\mathbf{Y}_{3 / 2}$ & $\mathbf{Y}_{2 / 1}$ & mean & $Y_{4 / 3}$ & $\mathrm{Y}_{3 / 2}$ & $Y_{2 / 1}$ & mean \\
\hline $\mathrm{Z}_{3 / 2}$ & 2.2 & 1.5 & 3.2 & 2.3 & 12 & 22 & 12 & 15.3 \\
\hline $\mathrm{Z}_{9 / 1}$ & 1.6 & 1.5 & 3.5 & 2.2 & 18 & 33 & 28 & 26.3 \\
\hline
\end{tabular}

1 See Fig. 3.

by large changes in angles, indicated by $\triangle \mathrm{A}$. In the case examined, an elongation of about $20 \%$ proved to be a critical value for crumbling. In this situation volume increase was also about $20 \%$.

A final point of interest is the distribution of the elongation over different parts of the furrow-slice. Table 5 shows the mean elongation of all lines of the blocks in the YZ-plane and Fig. 12 shows the elongation of all lines of the blocks separately.

The elongation, especially in the direction of travel (X), with a non-crumbling furrowslice was much smaller thans with a crumbling furrow-slice. In this direction even a slight compression was found: $\Delta \mathrm{L}=-0.7 \%$. Positive elongation mainly occured in the $\mathrm{Y}$ and $\mathrm{Z}$ direction: $\Delta \mathrm{L}=+5.0 \%$. Unlike the elongation with a crumbling furrow-slice, the elongation with a non-crumbling one was greatest near to the point of the plough share, and the elongation at the head of the slice equalled the elongation at the bottom.
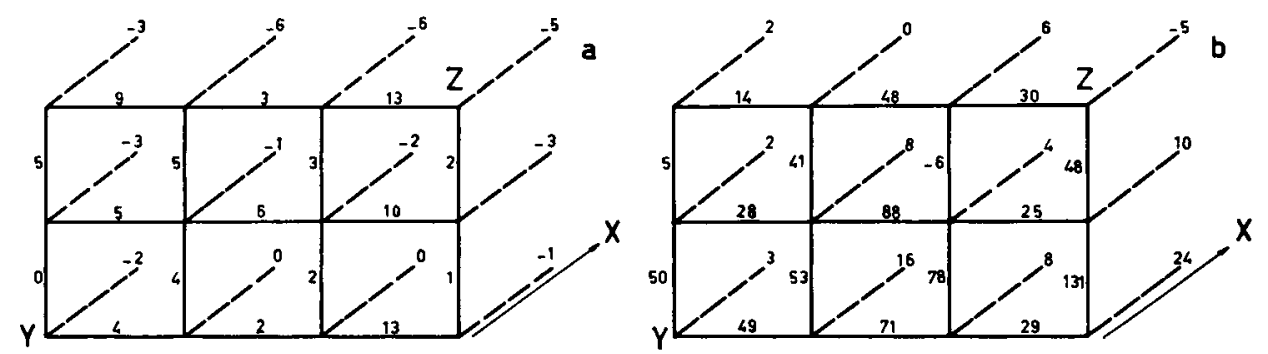

Fig. 12. Elongation of the lines in the $X, Y$ and $Z$ direction with a non-crumbled (a) and a crumbled (b) furrow-slice (left-turn mould-board). 

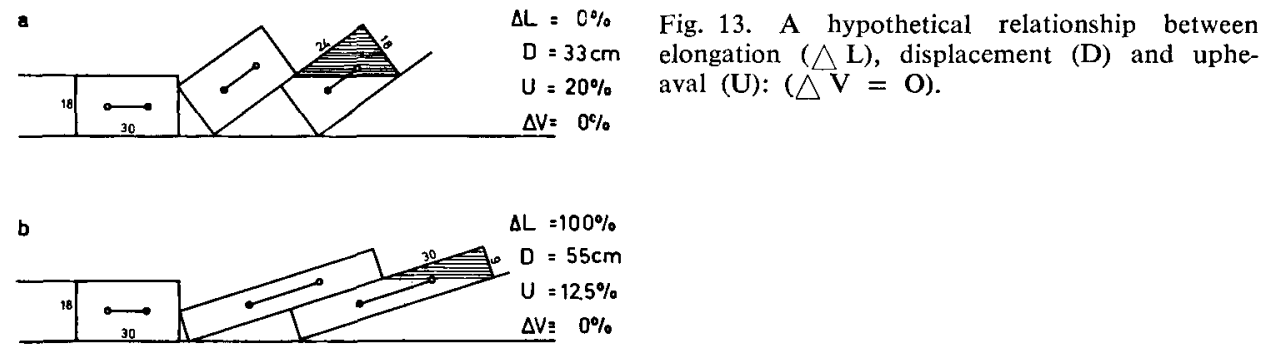

\section{Discussion}

In field trials a mean elongation at the original furrow-bottom of $97 \%$ was measured, whereas upheaval is known to be about 25-30 \% (Söhne, 1956, Poesse and van Ouwerkerk, 1967, Bosse and Kunze, 1970).

At first sight these two observations do not seem to agree. Mean elongation was calculated from regression coefficients that characterized soil displacement. It is possible to calculate mean upheaval from the relation between upwards displacement and $\mathrm{dfw}$ if the regression coefficient of sidewad displacement is higher than 2 , as it normally is. An elongation of $163 \%$ and a calculated upheaval of $34.5 \%$ demonstrate that large values of elongation at the furrow-bottom do not imply large volume increases.

Another demonstration of the restricted importance of elongation for upheaval is given in Fig. 13, where a schematic drawing of furrow-slices is given, where volume in the slices is kept constant and where in case a) elongation is $0 \%$ and upheaval $20 \%$ and in case b) elongation is $100 \%$ and upheaval only $12.5 \%$.

The relation between elongation and volume increase was discussed in more detail in section 'Result of soil bin experiments'. In general the relationship between elongation and volume increase was rather close in non-crumbling soil, where both values were smaller than $20 \%$.

Higher elongations were accompanied by soil crumbling and then elongation is no longer a suitable indicator for volume changes.

\section{Conclusions}

- Measuring the displacement of the soil by markers at the bottom of the furrow-slice could be done easily and quickly. Only the sides of the furrow-slice presented difficulties. Therefore, only rectilinear relationships were prepared, though actually other relationships are possible.

- Deformations within the furrow-slice were studied in a soil bin by placing markers systematically within the slice. Greatest deformations occurred at the bottom of the furrow-slice and near the point of the plough share.

- The variables, plough, soil and speed of travel, influenced mean soil displacement, transport of the furrow-slice into the direction of travel and elongation.

- Lighter and less mature soils were attended by more displacement: minimum displacement occurred at a speed of travel of about $4 \mathrm{~km} / \mathrm{h}$. 
- In the field, the mean turning angle was $149^{\circ}$ with a width-depth relation of $1.4: 1$. The transport angle was smaller than was expected from literature.

- The elongation was increasing with lighter soils; maximum elongation was found at a working speed of about $4 \mathrm{~km} / \mathrm{h}$.

- With a non-crumbling furrow-slice, changes within it, characterized by the elongation, were greatest near the point of the share. Less happened in the centre of the slice and there was not much difference between changes in the top or the bottom of the slice. With a crumbling furrow-slice much occurs at the bottom and at the centre and above the share-point.

- Elongation did not explain much of the upheaval but did explain much of the amount of crumbling and changes within the furrow-slice.

- Upheaval is a characteristic of total increase of pore space as a result of the ploughing action, but gives little information about changes within the furrow-slice.

- Besides the upheaval, the elongation is an important characteristic of ploughing.

\section{Acknowedgments}

The authors wish to thank Mr G. J. Poesse (Institute for Agricultural Engineering and Rationalization) for co-operation with field and soilbin trials, $\mathrm{Mr} \mathrm{C}$. A. Hoveyn (Institute for Biological and Chemical Research on Field Crops and Herbage) and $\mathrm{Mr} \mathrm{Th}$. A. Reesink (Department of Mathematics, Agricultural University) for their mathematical work.

\section{References}

Bosse, O. \& A. Kunze, 1970. Investigations of the loosening effects of various soil cultivation implements and the dynamics of soil statification in a loamy sand. Albr. Thaer Arch. 14: 813-828.

Feuerlein, W., 1960. Die Pflugarbeit und ihre Beurteilung. Grndl. Landt. 12: 44-50.

Feuerlein, W., 1962. Bewertungsmethoden für das Pflügen. Landtech. Münch. 17: 82-85.

Feuerlein, W., 1964. Pflügen oder was sonst? Landtech. Münch. 19: 708-711.

Feuerlein, W., 1966. Die Beurteilung des Pflügens. Landbauforschung 16: 31-36.

Feuerlein, W., 1968. Messmethoden und Kenngrössen zur Ermittlung des Arbeitserfolges beim Pflügen. Grndl. Landt. 18: 65-77.

Feuerlein, W., 1969. Die Messung der Pflügarbeit. Landtech. Münch. 24: 196-202.

Klooster, J. J., 1968. Ristertypen en ploegsnelheden. Rapp. Inst. LandbTech. Ration. 127.

Kuipers, H., C. van Ouwerkerk and G. J. Poesse, 1966. The characterization of soil structure changes produced by tillage operations. Grundförbättring 19: 59-75.

Nichols, M. L. \& I. R. Reed, 1934. Soil dynamics. VI. Physical Reactions of soils to mould-board surfaces, Agric. Engng. 15: 187-190.

Poesse G. J. en C. van Ouwerkerk, 1967. Ristervorm en ploegsnelheid. Publ. Inst. LandbTech. Ration 103

Rid, H. \& A. Süss, 1968. Zur Methodik der Prüfung des Effekts von Bodenbeararbeitungsgeräten. Landtech. Forsch. 10: 62-70.

Söhne W., 1959. Untersuchungen über die Form von Pflügkörpern bei erhöhter Fahrgeschwindigkeit. Grndl. Landt. 11: 22-39.

Steenberg, K. \& A. Njøs, 1964. Vertical distribution of $\mathrm{P}_{32}$ labelled $\mathrm{NH}_{4} \mathrm{H}_{2} \mathrm{PO}_{4}$ after tillage opsrations with a mould-board plough and rotary cultivator. J. agric. Engng. Res. 9: $241-244$. 